\title{
Application of roller burnishing technologies to improve the wear resistance of submerged pump parts made of powder alloys
}

\author{
Elena Kropotkina, Marina Zykova, Alexander Shein*, and Natalya Kapustina \\ Moscow State University of Technology "STANKIN", 1 Vadkovsky per., GSP-4, Moscow 127994, Russian Federation
}

Received: 30 January 2019 / Accepted: 21 March 2019

\begin{abstract}
This paper presents experimental studies of the influence of surface plastic deformation (SPD) (roller burnishing) on the properties of the surface layer of a part "guide apparatus" of the centrifugal submersible pump for oil production. The parts made of composite powder alloys based on the iron-copper system were taken as an object of researches. The microstructure of the surface layer of the samples, surface roughness, microhardness, and hardness were studied. Testing of the samples for the surface layer resistance to abrasive wear according to the Calotest method showed a decrease in the wear intensity by $1.5-1.6$ times in comparison to samples without SPD.
\end{abstract}

Keywords: Roller burnishing / wear / resistance / powder alloys / pump parts / microstructure / hardness

\section{Introduction}

At present, the issues related to an increase in the operating life of the equipment used in the oil industry are of high importance. Exploitation conditions of such products are extremely complicated as there are significant loads, high temperatures, and chemical and abrasive effects [1-4]. Oil-producing equipment parts quickly wear out, and it is necessary to repair or replace them timely and uninterruptedly.

Today, multistage centrifugal pumps are widespread due to their apparent advantages, among which are the continuity of the liquid medium, the simplicity of the device, sufficiently high efficiency, and right suction height [5-7]. The total length of such pumps can reach $10 \mathrm{~m}$, and the number of stages is up to 500. The design of centrifugal submersible pumps for oil production provides traditionally for the installation of a set of steps in the pump casing, each of which consists of a rotating impeller and stationary guide vanes (Fig. 1).

Industrial experience of the operation of centrifugal submersible pumps for oil production shows that about $50 \%$ of their failures are connected with wear and tear of parts of pump stages such as an impeller and guide vanes. These parts experience the maximum level of contact friction and cyclic loads during operation in comparison with other pump elements. It can be explained by the simultaneous impact on the parts of forces arising from the

\footnotetext{
* e-mail: a.shein1978@gmail.com
}

rotation and associated with its oscillations, as well as loads in the interaction of working surfaces with the fluid of the well.

It should be noted that the operating life of an impeller and guide vanes is more than twice as short as the life of the other main parts of the pump. The different operating life of pump elements and terms of scheduled repair lead to a significant decrease in the efficiency of submersible centrifugal pumps operation. Thus, according to various researchers [8-10] and in compliance with existing technical regulations and standards, in the process of operation a pump casing serves up to $5 \mathrm{yr}$, a pump shaft, heads, and a cable do up to 3-4 yr, and the operating life of an impeller and guide vanes does not exceed 1.5-2 yr $[11,12]$. The given data are slightly averaged: it mostly depends on specific factors, which are typical for a particular oil field, but reflects the general statistics $[13,14]$.

Analysis of experimental studies by various authors allows systematizing mechanisms of wear of submersible pumps critical parts for oil production. Among the existing variety of causes of wear and tear, we can highlight the predominant ones. Figure 2 illustrates the typical types of wear and loss of operating state of the submersible pump guide vanes [15-17].

Abrasive wear is mechanical wear of material surface formed because of cutting, hitting, and scratching by solid particles. In this case, the surface layer of the metal is mechanical abrasion and distortion of the geometric dimensions of the cooperating parts. Common pairs in couplings as "shaft-bearing", "shaft-impeller hub of the pump", and "impeller support surface - guide vanes support flange" often cause this type of wear. 
Varieties of abrasive wear parts of submersible pumps are hydro- and vibro-abrasive wear [18]. The hydroabrasive wear results from the mechanical wear of the submersible pump part material because of the cutting or scratching action of solids in the process fluid stream. Vibro-abrasive wear is caused by vibrations and unbalanced forces that affect the condition of the friction surfaces between which high hardness mechanical impurities (abrasive) may be present [19]. The presence of abrasive in combination with the significant contact force of the friction surfaces leads to catastrophic wear of the pump parts.

Mechanical impurities contained in the pumped liquid (sand, proppant particles, solids, metal fragments, etc.) contribute to the intensification of wear process. They often cause premature breakdowns of oil production pumping equipment. In the case of unsecured fluid inflow (insufficient reservoir pressure and bottom-hole pressure), stagnation and blockage by mechanical particles of the guide vanes can be observed: it leads to inevitable failure of the centrifugal pump stage [20].

The quality of the pump parts manufacturing, in particular, used manufacturing technologies and chemical composition of structural material, provides a significant

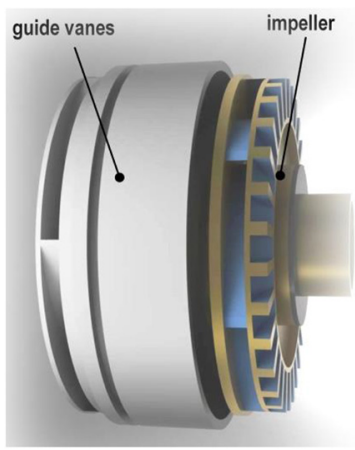

(a)

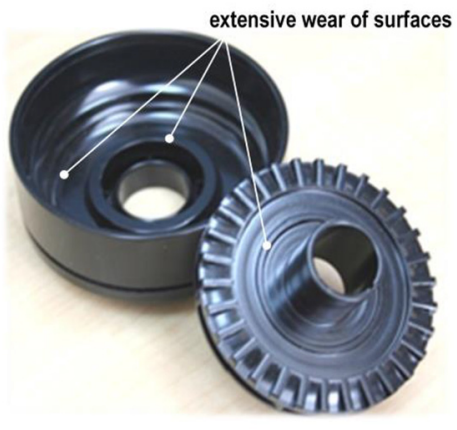

(b)
Fig. 1. 3D representation of the stage centrifugal pumps - a general view: (a) an impeller and guide vanes used in the design of the centrifugal vortex pump in the assembly, developed by Novomet JSC (Perm, Russia); (b) the surfaces of extensive wear. impact on the operating life [21]. The geometry of pump parts determines the most common technologies of their manufacture such as casting into sand molds or powder metallurgy. Methods of manufacturing submersible pump units through a combination of forging and welding of stainless steel parts were also developed. Besides, it is necessary to mention promising liquid crystal polymers, which can be used to manufacture components of centrifugal pumps $[22,23]$. However, such materials cannot be realized in a wide range of downhole conditions due to the low heat resistance of products made of them [18].

In earlier years, the casting technology was used to produce pump parts made of grey cast iron. Due to the reduced operating life of grey cast iron parts, this material must now be recognized as obsolete. For critical submersible pump parts, the material, which holds more promise, is the nickel cast iron with an austenitic structure (Ni-resist) [24]. Casting technology is cheaper than powder technology but needs to be improved to give the required surface properties. In casting, the main type of scrap is the presence of surface defects in the form of pores and caverns [25]. It is connected with technological parameters of casting and use of molding and finishing sands, which do not provide high gas permeability and formation of burns. The issues as mentioned above can reduce the operating life of parts and units of submersible pumps radically.

Figure 3 shows the characteristic type of surface defects of the submersible pump guide vanes formed during the casting into sand molds. It should be emphasized that for the sake of clarity, the figure especially presents an obvious defect; such guide vanes will not be allowed into operation [26]. However, even a small number of pores formed in the surface layer of the part during casting can lead to premature loss of operability. Powder metallurgy technologies exclude the defects that are observed in casting technologies.

Thus, the impeller and guide vanes are the elements in the submersible pump stage design that limit the basic operating parameters of the pump. Therefore, it is crucial to develop various technological solutions, which ensure the reduction of the wear rate of the surface layer of critical parts of centrifugal submersible pumps for oil production. One such answer is the use of various methods of surface treatment (hardening) [27]. MSTU "STANKIN" has a long

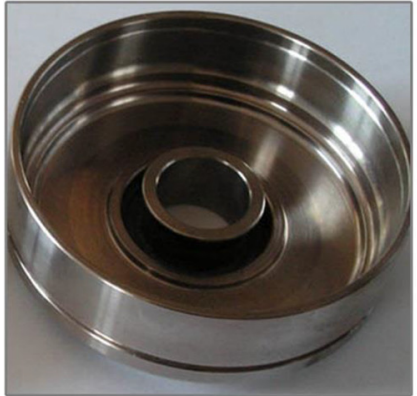

(a)

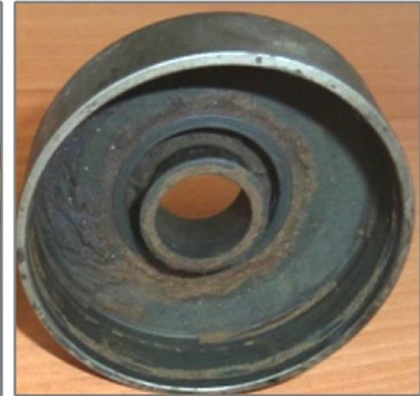

(b)

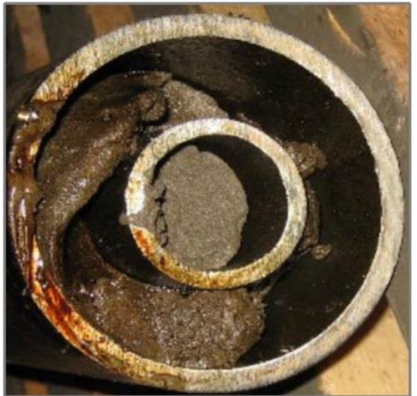

(c)

Fig. 2. Typical wear and failure of the guide vanes of submersible pumps: (a) a wear-free part before an operation, (b) a part with the traces of abrasive wear, (c) a part with a presence of blockage by mechanical particles. 


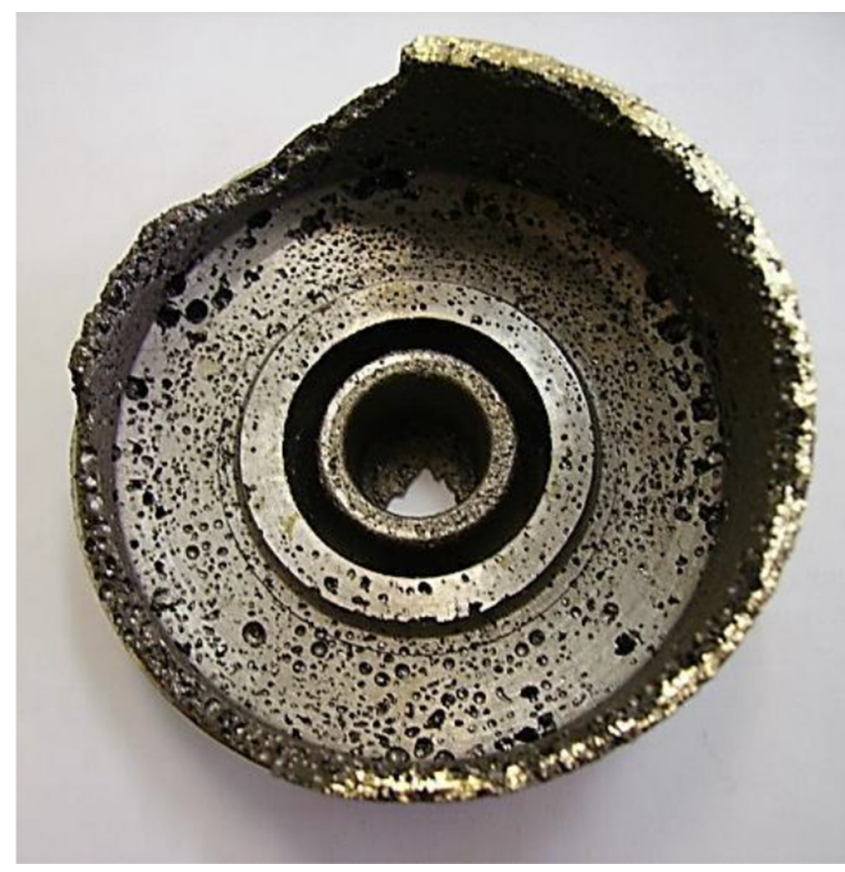

Fig. 3. Typical defects of the submersible pump guide vanes formed during casting: pores and caverns.

and successful experience of development and practical application of the technology of parts hardening for the needs of mechanical engineering [28-30].

Electro-physical strengthening increases the cost of parts production due to the need to purchase new equipment and the appearance of additional process operation. Besides, it requires strict temperature control to prevent softening of the surface layer. Many of the known electro-physical methods cannot be used to harden submersible pump parts as they use concentrated energy sources and heating of the surface layer to temperatures that exceed the heat resistance of the structural material [31-33].

Surface plastic deformation (SPD) is a prospective method due to advantages related to its low cost (the technology may be carried out by classic metal-cutting machines with an additional device), low labor input, and absence of any industrial waste. The application of SPD methods allows reducing the surface roughness, transforming the surface layer structure, increasing its hardness, etc.

The purpose of this work is the increase of the wear resistance of the mating surfaces of guide vanes through the usage of the original technology of pressing parts from composite powder alloys and subsequent strengthening of parts by SPD such as roller burnishing.

The main task of the research is the study of the influence of SPD technology on the properties of the mating surfaces of the centrifugal submersible pump guide vanes made of composite powder alloys from the iron-copper system.

It should be noted that today the overwhelming majority of published works related to the study of SPD processes were performed for monolithic parts obtained by casting, forging, and other methods [34]. SPD technologies
Table 1. The chemical composition of materials used in research.

\begin{tabular}{lllllll}
\hline No. & Material & \multicolumn{5}{c}{ Content (\%) } \\
\cline { 3 - 7 } & & $\mathrm{Cr}$ & $\mathrm{Ni}$ & $\mathrm{Cu}$ & $\mathrm{C}$ & $\mathrm{Fe}$ \\
\hline 1 & $\mathrm{Fe} / \mathrm{Cu} 15$ & - & - & 15 & 1 & Basis \\
2 & $\mathrm{Fe} / \mathrm{Cu} 20 / \mathrm{Cr} 11 / \mathrm{Ni} 8$ & 11 & 8 & 20 & - & Basis \\
\hline
\end{tabular}

for the parts produced from $\mathrm{Fe}-\mathrm{Cu}$ alloys using powder metallurgy remain practically unexplored. This object of current research is critical for the modern oil industry.

In the present work, the research was implemented for the typical parts of submersible pumps as guide vanes that were produced and investigated at the experimental production, and at the laboratory and technological ground of Novomet JSC (Perm, Russia).

\section{Materials, original equipment, experimental techniques, and tools}

Two types of composite powder materials based on the iron-copper system were used for the production of "guide vanes" parts, which were subsequently subjected to roller burnishing: $\mathrm{Fe} / \mathrm{Cu} 15$ and $\mathrm{Fe} / \mathrm{Cu} 20 / \mathrm{Cr} 11 / \mathrm{Ni}$. The chemical composition of the materials used is given in Table 1 .

These materials in the literature are called " $\mathrm{Fe}-\mathrm{Cu}$ pseudo-alloys" $[35,36]$. They include both two-component composite materials and multicomponent alloys based on $\mathrm{Fe}$ and $\mathrm{Cu}$. The pseudo-alloys have excellent anticorrosive and damping characteristics, which makes these composites suitable for the production of compressor blades, gear wheels, turbine rotors parts, etc.

The original technology includes the following stages [37]: powder mixture preparation; separate pressing of the parts to obtain workpieces of a given shape, sizes, and density (Fig. 4); applying of the fine powder suspension of the same alloy composition on the joined surfaces; and sintering, which combines with diffusion welding and infiltration by copper.

Before assembly, the suspension of fine powder of the same alloy is applied to the parts to be assembled, and they are glued together with the help of a special slip (Schlicker). After that, the pieces are placed in the container, which is brought into contact with copper billets, and the remaining volume of the container is filled with backfill containing $99 \%$ of aluminum oxide and $1 \%$ of graphite.

Further, the workpieces are sintered in combination their diffusion welding with copper infiltration in hydrogen medium at the temperature of $1150{ }^{\circ} \mathrm{C}$ for $3 \mathrm{~h}$. The porous layer which forms between the jointed surfaces allows carrying out infiltration evenly the entire volume of the guide vanes by copper, which increases the strength of the connection and contributes to an increase of anticorrosive and anti-erosive properties. A dimension shrinkage, density, and grain-to-grain contact increase as the temperature and sintering time rise. Then the sintered workpiece is processed on metal-cutting machines. 


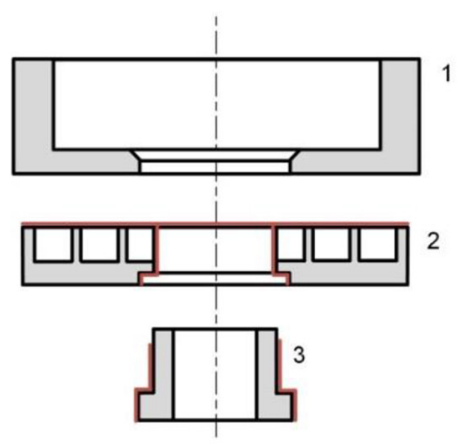

(a)

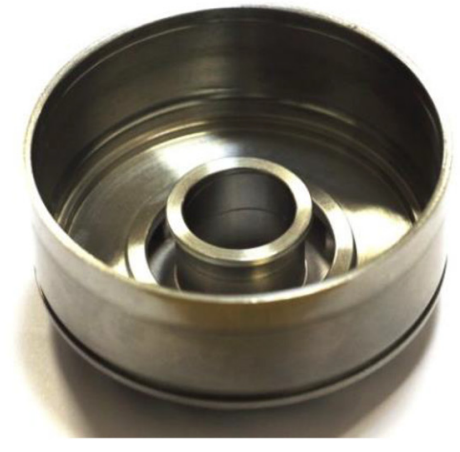

(c)

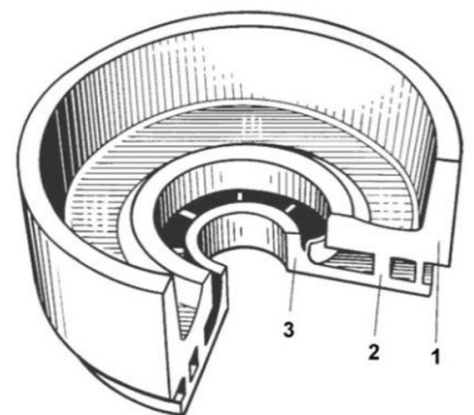

(b)

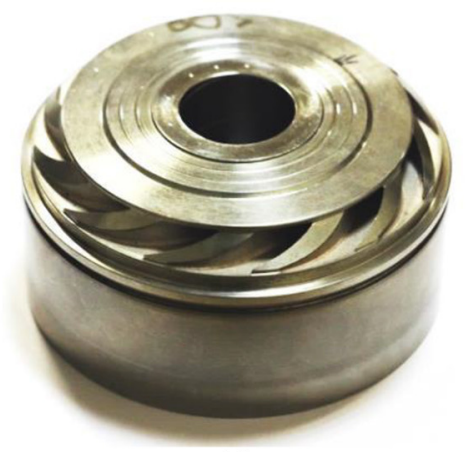

(d)

Fig. 4. Guide vanes of the centrifugal submersible pump for oil production: (a) a schematic representation of the guide vanes before assembly, (b) numbers indicating the assembly elements, (c, d) a general view of the guide vanes after assembly.

Tear strength of the obtained face joint was about $100 \mathrm{MPa}$ without copper impregnation and $500 \mathrm{MPa}$ with it. After sintering with impregnation, the force, which is required to press the bushing from the cover with blades, was $30 \mathrm{kN}$ at the contact area of $580 \mathrm{~mm}^{2}$. Distortion of the finished part or delamination of workpieces was not observed. The described method allows producing the working parts of submersible pumps, which are identical in design with casted parts, by powder metallurgy.

Figure 4 presents the guide vanes which were hardened by roller burnishing, one of the SPD methods. Mating surfaces, as, in particular, a support flange, were hardened using experimental technology. The surfaces subject to the most intense wear, as it was discussed above (Figs. 1 and 2) marked with red in Figure 4a.

Roller burnishing was performed on the CU $500 \mathrm{M}$ universal turning machine manufactured by ZMM (Sliven, Bulgaria) by the usage of special preinstalled devices (Fig. 5).

The machining conditions were chosen based on providing the optimum pressure on the part surface. It is known that the roller pressure depends on the force and contact area between the roller and part. The size of the contact area depends on the tool geometry - a diameter and profile radius of the roller - and the part dimensions [38].

The feed rate was set taking into account the same number of repetitive deformations at one point of the part surface during roller burnishing. The degree of feed

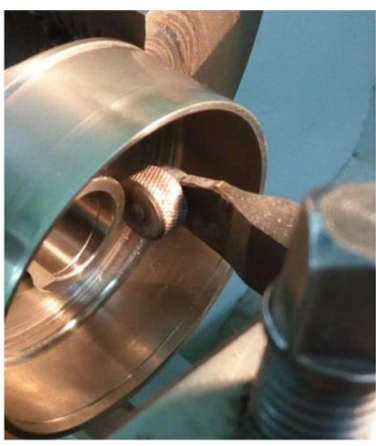

(a)

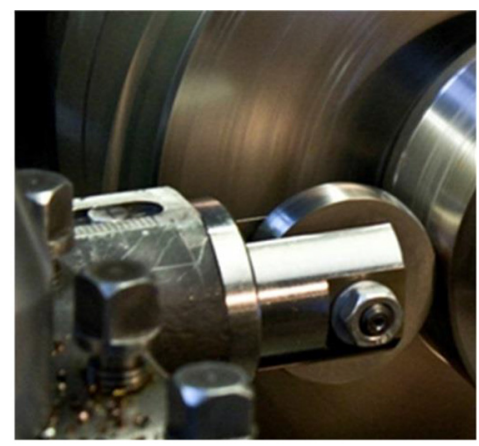

(b)
Fig. 5. A general view of the special device for fastening of the parts on the lathe machine for roller burnishing: (a) for flat surfaces, (b) for cylindrical surfaces.

influence was related to the size of the deformation zone, in particular, to the width of the contact spot, and can be characterized by the parameter $k_{s}$, which determines the multiplicity of the load application [39]:

$$
k_{s}=\frac{2 b}{s} \cdot m,
$$

where $S$ is a feed rate, $2 b$ is a width of roller contact spot and part in the feed direction, which depends on the radius of the roller profile and part diameter, and $m$ is a number of longitudinal strokes of the roller. 
Since the speed of machining does not have a significant impact on the quality of the surface layer, the number of part revolutions was assigned based on the requirements of obtaining optimal machining performance and eliminating an increase of the temperature in part during rolling. When assigning the conditions, we relied on the previous experience of research work.

The specimen made of $\mathrm{Fe} / \mathrm{Cu} 15$ material was processed with a $60 \mathrm{~mm}$ diameter roller with an $R=20 \mathrm{~mm}$ profile radius. Processing conditions were next: a rotational speed $n=315 \mathrm{rpm}$, a feed rate $S=0.2 \mathrm{~mm} / \mathrm{rpm}$. The specimen made of $\mathrm{Fe} / \mathrm{Cu} 20 / \mathrm{Cr} 11 / \mathrm{Ni} 8$ material was processed with a roller $30 \mathrm{~mm}$ in diameter and a profile radius of $R=5 \mathrm{~mm}$. Processing conditions were next: a rotational speed $n=250 \mathrm{rpm}$, a feed rate $S=0.1 \mathrm{~mm} / \mathrm{rpm}$. During the experiments, a roller burnishing force $P$ was: $1700 \mathrm{~N}$ (mode $\mathrm{N} 1$ ) and $2610 \mathrm{~N}$ (mode $\mathrm{N} 2$ ) for $\mathrm{Fe} / \mathrm{Cu} 15$ and $\mathrm{Fe} / \mathrm{Cu} 20 /$ Cr11/Ni8 correspondingly.

A set of characteristics before and after roller burnishing were studied during further testing, in particular, the microstructure of produced parts, surface roughness, microhardness, and hardness.

Metallographic analysis of powder steels was performed on a GX-51 microscope by Olympus (Tokyo, Japan) at magnification $\times 50-1000$. Samples were photographed using the specialized software complex Video Test Master Structure (Zwick Roell, Ulm, Germany).

Microhardness of the hardened layer of samples was carried out on a PMT-3M hardness tester (LOMO, Saint Petersburg, Russia) at maximum magnification $\times 800$ by pressing a Vickers diamond tip with a square base of a tetrahedral pyramid. This method provides a geometric and mechanical similarity of prints as the indenter deepens into the material under the influence of a load of $50 \mathrm{~g}$.

The hardness of the surface layer of the samples was determined by the Rockwell method by the difference in applied loads to the samples. Initially, a preload was applied, and then the total load was applied, at which time the indenter was inserted into the sample and hold there for a certain period. For the softer $\mathrm{Fe} / \mathrm{Cu} 15$ material, the hardness was measured on the HRB scale, where the indenter was a steel hardened ball. The hardness of $\mathrm{Fe} / \mathrm{Cu} 20 / \mathrm{Cr} 11 / \mathrm{Ni} 8$ was measured on the HRC scale using a diamond cone.

The samples were etched to reveal its grain boundaries in $4 \%$ nitric acid solution in ethyl alcohol and Oberhoffer reagent for the study of its microstructure.

The surface roughness of the samples before and after roller burnishing was studied by the Hommel Tester T8000 profiler, Jenoptik Industrial Metrology (VillingenSchwenningen, Germany).

The resistance of the surface layer of the samples to abrasion was carried out using tests on the Calotest device, CSM Instruments SMTnet (Freiburg im Breisgau, Germany). The principle of testing is as follows (Fig. 6). The rotating sphere is located on a test sample with a preselected load. The rotation of the sphere is carried out using the drive shaft. The position of the sphere to the test sample and the load in the contact area is constant. Load monitoring is carried out using a special sensor. While the sphere rotates on the surface of

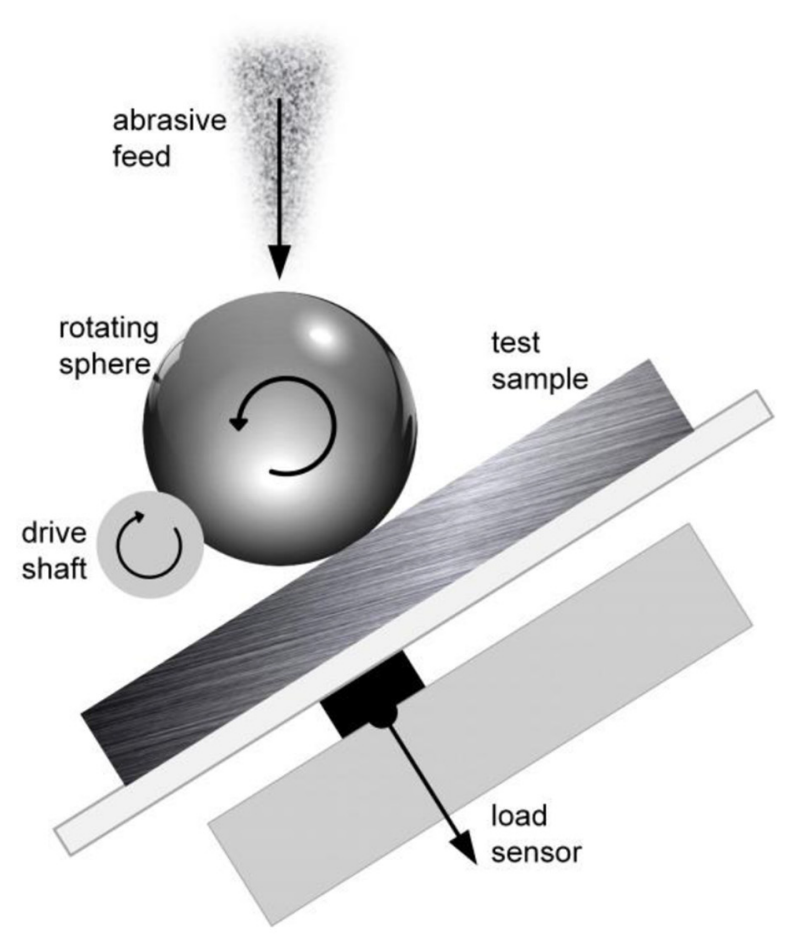

(a)

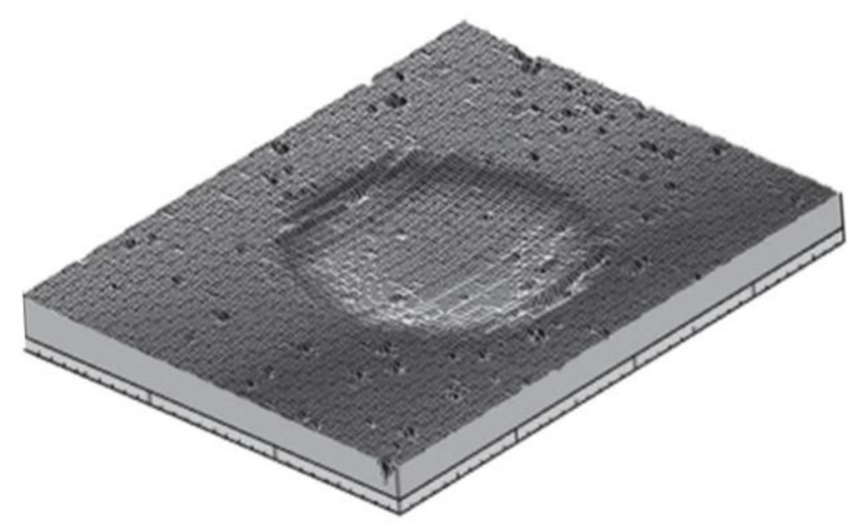

(b)

Fig. 6. A principle scheme for testing of the initial samples and obtained specimens on the resistance of the surface layer to abrasion: (a) test scheme, (b) typical 3D image of the wear hole on the specimen after the tests.

the test sample, a water-based abrasive suspension is fed into the test area. Particles of the abrasive suspension in the area of contact between the sphere and the test sample result in abrasion of the part surface and the formation of a spherical wear hole. Optical analysis of the geometric dimensions of the obtained hole allows us determining the intensity of abrasive wear of materials. In particular, the model of abrasive wear can be used, which fully corresponds to the Archard equation [40]. 


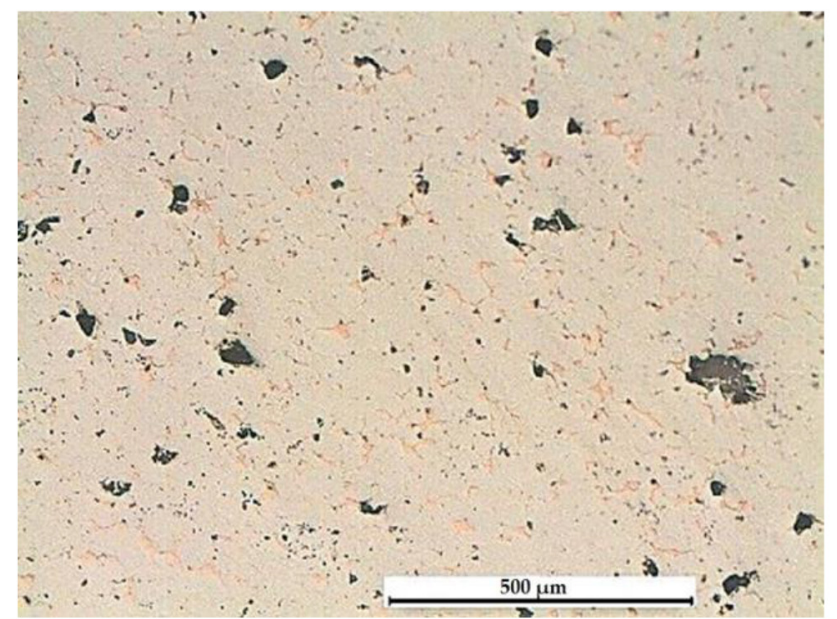

(a)

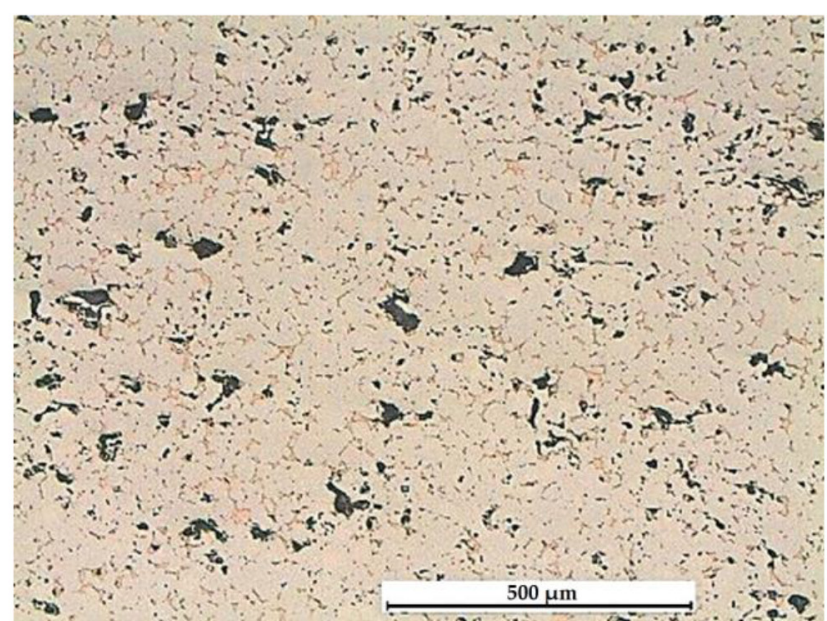

(b)

Fig. 7. The microstructure of the samples made of composite powder alloys from the iron-copper system by original pressing technology (before etching): (a) Fe/Cu15, (b) Fe/Cu20/Cr11/Ni8.

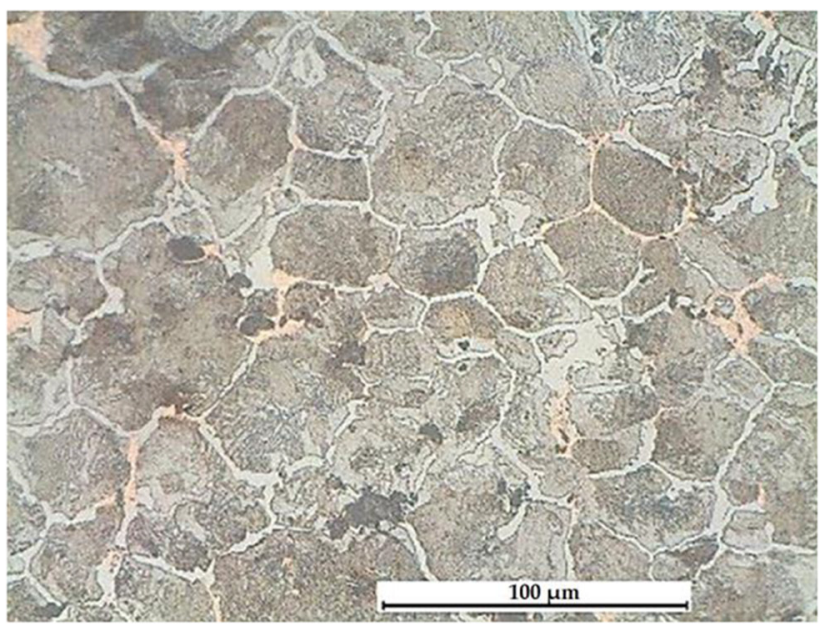

(a)

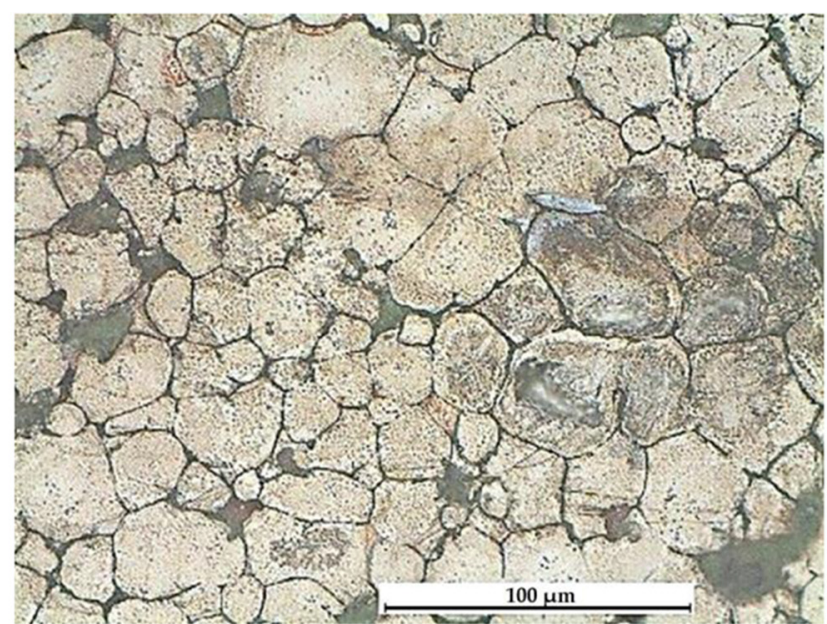

(b)

Fig. 8. The microstructure of the samples made of composite powder alloys from the iron-copper system by original pressing technology (after etching): (a) Fe/Cu15, (b) Fe/Cu20/Cr11/Ni8.

The wear volume of material $V$ can be calculated by the equation:

$$
V=\left(\frac{\pi \cdot d^{4}}{64 R}\right),
$$

where $d$ is a diameter of the wear hole and $R$ is a radius of the rotating sphere.

The intensity of wear $K$ can be evaluated with use of the wear volume of material $V$, as these two values are related as follows:

$$
K=\frac{V}{L \cdot F_{N}}=\frac{\pi \cdot d^{4}}{64 R \cdot L \cdot F_{N}}
$$

where $L$ is a slip distance and $F_{N}$ is a normal load on the sample.

\section{Results of experimental studies}

The microstructure study of the samples manufactured by described above technology of powder alloy pressing with subsequent infiltration by copper melt showed the following results (Figs. 7 and 8 ).

The samples made of $\mathrm{Fe} / \mathrm{Cu} 15$ alloy have an initial pearlite-ferrite structure with a cementite network and copper inclusions. Formation of the cementite network is conditioned by the hypereutectoid carbon content of the material. The microstructure of $\mathrm{Fe} / \mathrm{Cu} 15$ samples contains 4-6 plate pearlite, sorbitol, ferrite, copper inclusions, and pores.

The samples made of high alloy $\mathrm{Fe} / \mathrm{Cu} 20 / \mathrm{Cr} 11 / \mathrm{Ni} 8$ have $\gamma$-phase with sorbitic- and bainitic-type austenite 
Table 2. The surface roughness of the samples before and after hardening.

\begin{tabular}{llll}
\hline Powder alloy & \multicolumn{2}{c}{ Surface roughness $(\mu \mathrm{m})$} \\
\cline { 2 - 4 } & & \multicolumn{2}{c}{ After roller burnishing } \\
\cline { 2 - 4 } & Refore roller burnishing & Processing at mode N1 & Processing at mode N2 \\
\hline $\mathrm{Fe} / \mathrm{Cu} 15$ & Ra 0.615 & Ra 0.411 \\
$\mathrm{Fe} / \mathrm{Cu} 20 / \mathrm{Cr} 11 / \mathrm{Ni} 8$ & Ra 1.6 & Ra 0.515 & Ra 0.495 \\
\hline
\end{tabular}

Table 3. The microhardness of the surface layer of the samples before and after hardening.

\begin{tabular}{llll}
\hline Powder alloy & \multicolumn{2}{c}{ Microhardness of the surface layer HV $(\mathrm{GPa})$} \\
\cline { 2 - 4 } & & \multicolumn{2}{c}{ After roller burnishing } \\
\cline { 2 - 4 } & Before roller burnishing & Processing at mode N1 & Processing at mode N2 \\
\hline $\mathrm{Fe} / \mathrm{Cu} 15$ & $2.1-2.9$ & $2.2-3.2$ & $2.3-3.3$ \\
$\mathrm{Fe} / \mathrm{Cu} 20 / \mathrm{Cr} 11 / \mathrm{Ni} 8$ & $2.2-3.3$ & $2.4-3.5$ & $3.2-3.8$ \\
\hline
\end{tabular}

Table 4. The hardness of the sample surface after hardening.

\begin{tabular}{lll}
\hline Powder alloy & \multicolumn{2}{c}{ Surface hardness $(\mathrm{GPa})$} \\
\cline { 2 - 3 } & Processing at mode N1 & Processing at mode N2 \\
\hline $\mathrm{Fe} / \mathrm{Cu} 15$ & $1.9(\mathrm{HRB})$ & $2.3(\mathrm{HRB})$ \\
$\mathrm{Fe} / \mathrm{Cu} 20 / \mathrm{Cr} 11 / \mathrm{Ni} 8$ & $2.2-2.3(\mathrm{HRC})$ & $2.8-2.9(\mathrm{HRC})$ \\
\hline
\end{tabular}

decomposition products and copper inclusions before SPD. After roller burnishing, the metallographic analysis did not show a deformed layer of samples. It was found that a white layer characterizes the microstructure of the hardened surface. Austenite, austenite degradation products, carbides, ferrite, copper inclusions, and pores represent the microstructure of $\mathrm{Fe} / \mathrm{Cu} 20 / \mathrm{Cr} 11 / \mathrm{Ni} 8$ samples.

Table 2 shows the results of surface roughness measurements of the samples made of $\mathrm{Fe} / \mathrm{Cu} 15$ and $\mathrm{Fe} /$ $\mathrm{Cu} 20 / \mathrm{Cr} 11 / \mathrm{Ni} 8$ powder alloys before and after hardening. Tables 3 and 4 present the results of Vickers microhardness and Rockwell hardness measurements of these samples.

It can be seen (Tab. 2) that SPD hardening of parts made of iron-copper powder alloys significantly affects the quality of their surface. As follows from the presented data, a deviation of the profile (Ra roughness) was 1.46-1.6 $\mu \mathrm{m}$ for samples that have not been hardened. It corresponds to the quality of the surface formed after finishing machining as turning or milling or some grinding operations. Surface roller burnishing reduces the Ra roughness to $0.41-0.61 \mu \mathrm{m}$ in dependence on the selected conditions.

The effect of SPD hardening on the microhardness and hardness values is less significant (Tabs. 3 and 4), but there was shown some positive impact as well. An increase in microhardness no more than 3-5\% was observed after processing of $\mathrm{Fe} / \mathrm{Cu} 15$ samples at various conditions of roller burnishing (with force $P=1700 \mathrm{~N}$ and $P=2610 \mathrm{~N}$ ). The effect was more appreciable after processing of the

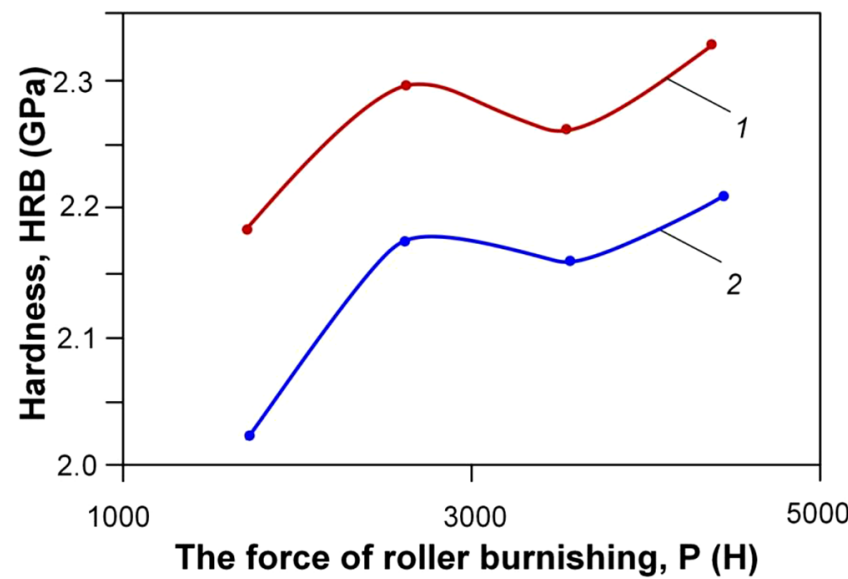

Fig. 9. Dependence of the surface layer hardness (HRB) on the force at processing of $\mathrm{Fe} / \mathrm{Cu} 15$ alloy by rollers with a radius of $R=60 \mathrm{~mm}$ at different roller profile radii: (1) is for $10 \mathrm{~mm}$ and (2) is for $20 \mathrm{~mm}$.

samples made of $\mathrm{Fe} / \mathrm{Cu} 20 / \mathrm{Cr} 11 / \mathrm{Ni} 8$ : microhardness increased up to $7-10 \%$.

It is obvious that the factor of force $P$ should seriously influence on the values of microhardness and hardness. It can be seen in Tables 3 and 4 that the hardening at mode $\mathrm{N} 2$ during all the experiments provided a more pronounced effect on these parameters.

As follows from the data presented in Figure 9, the hardness of $\mathrm{Fe} / \mathrm{Cu} 15$ sample increases as the force 

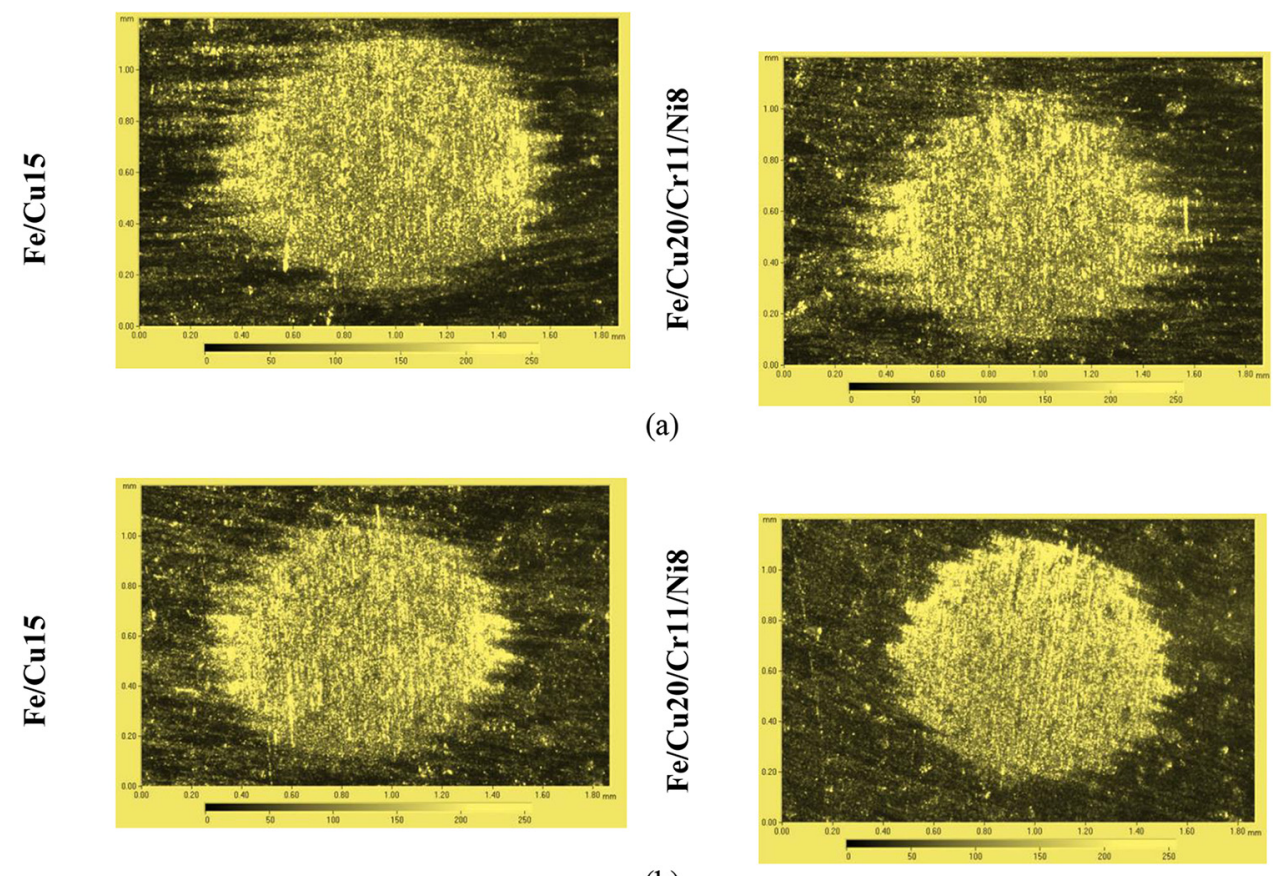

(b)
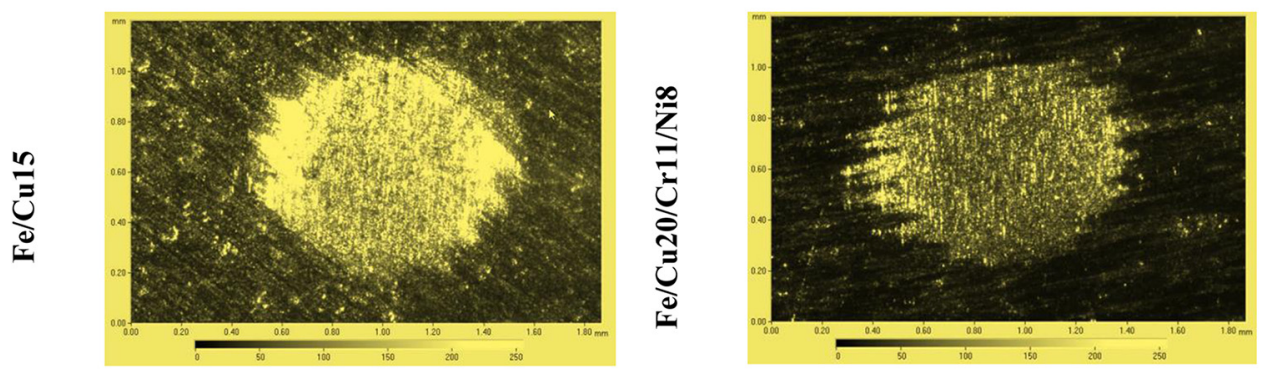

(c)

Fig. 10. 2D images of wear well on samples after surface wear resistance tests for 3 min: (a) before hardening, (b) after hardening at mode N1, (c) after hardening at mode N2.

increases. At $P=2610 \mathrm{H}$, the hardness value has a maximum after which it begins to decrease and reaches a minimum at $P=3700 \mathrm{~N}$. Then it starts to increase again. Besides, it is important to note that the radius of the roller profile also has a strong influence on the hardness of the surface layer: the hardness of the surface layer decreases as the radius of the roller profile increases (Fig. 9). The same regularity was observed in the study of the samples made of $\mathrm{Fe} / \mathrm{Cu} 20 / \mathrm{Cr} 11 / \mathrm{Ni} 8$.

Further express tests on the stability of the specimen surface layer to abrasive wear on the Calotester showed a significant impact of roller burnishing and hardening conditions. Figure 10 shows 2D images of the wear hole on the samples of two investigated powder alloys after the tests within $3 \mathrm{~min}$. The difference between the sizes of the formed wear wells is visible. The intensity of the wear process can be reduced by assigning rational roller burnishing conditions.

Figure 11 shows the data illustrating the dependence of the amount of wear material on the time during express tests for the resistance to abrasive wear (the amount of wear material was calculated using Eqs. (2) and (3)). The presented diagrams give some idea about the kinetics of wear development over time depending at different modes of roller burnishing.

\section{Discussion}

It is known that significant complex structural and phase transformations occur in the surface layer as a result of elastoplastic deformation of monolithic (solid) steels by plastic deformation. The powder material differs significantly from the monolithic material and represents a certain set of particles. They are capable of plastic deformation due to the plastic shift of the particle population, as well as due to the sliding of contacting particles relative to each other.

Detailed metallographic analysis of two types of samples of composite powder materials from the ironcopper system as $\mathrm{Fe} / \mathrm{Cu} 15$ and $\mathrm{Fe} / \mathrm{Cu} 20 / \mathrm{Cr} 11 / \mathrm{Ni} 8$ has not revealed any visible changes in the near-surface zones of the 


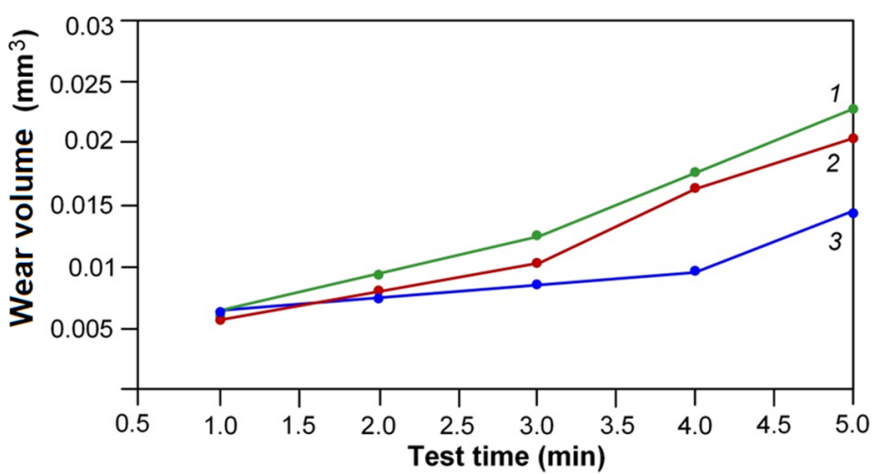

(a)

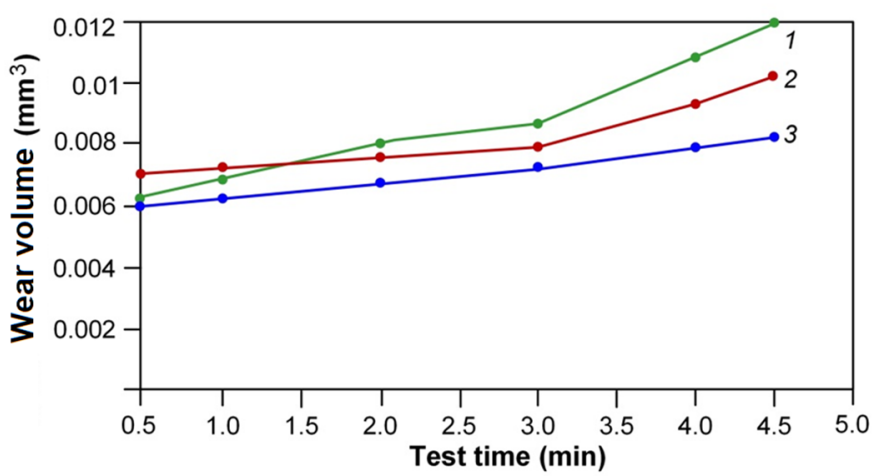

(b)

Fig. 11. The temporal dependence of the wear volume of material during rapid abrasion tests: (a) Fe/Cu15, (b) Fe/Cu20/ Cr11/Ni8; (1) before hardening, (2) after hardening at mode N1, and (3) after hardening at mode N2.

samples under study. Therefore, it should be assumed that the hardening of parts made of powder materials is achieved by increasing the density of dislocations. The increase in dislocation density leads to the formation of both parallel dislocations and dislocations in different layers and directions. Thus, dislocations interfere with each other's movements and the hardness of the source material increases. Undoubtedly, further theoretical and experimental study of the powder hardening mechanism using SPD technology is necessary and will be continued.

It was established that the characteristics of the surface layer of the samples made of iron-copper powder alloy (roughness, microhardness, and hardness) are determined by the force of roller burnishing (deformation). As the force increases, the roughness slightly decreases and the hardness increases. However, this tendency persists up to a certain stage: after increasing the force over $2650 \mathrm{~N}$, the process begins to destabilize and to develop an excessive hardening of the surface. It leads to the effect of the rolled surface peeling. Then the surface layer becomes more fragile, and the surface roughness and hardness increase. It should be noted that the surface layer, which is formed during excessive hardening, is defective and cannot withstand operational loads [41-44].

The analysis of the study results of the roughness and hardness of the samples made of the iron-copper powder alloy on the applied force has shown the following: the obtained regularities are not linear; the roughness changes according to the parabolic law; a change in microhardness and hardness is described by a more complicated dependence with two extremes.

Another critical factor which is necessary to note is the feed rate and its impact on the surface layer to be formed. The experiments that were carried out earlier showed that the surface roughness decreases as the feed rate reduces. However, the roughness decreases to a particular stage and then it begins to increase. A similar regularity was described in the works of other researchers for solid monolithic materials of the samples [45,46]. Although the effect of the feed rate is much less than the impact of the roller burnishing force, this factor should be chosen to be optimal for each specific material. We have established that the optimal feed rate when rolling parts made of composite materials of the iron-copper system is in the range of $0.1-0.2 \mathrm{~mm} / \mathrm{rev}$.

It is important to note the effect of the profile radius of the roller, which is used during machining. The following dependence was established in work: as the radius of the roller increases, the hardness decreases, and the roughness slightly increases. It is related to a decrease of the "effective" contact area between a tool and part and a reduction of pressure per unit of the surface area as the radius of the roller profile increases.

As it was determined the rotational speed and the number of working strokes have little effect on the roughness but do not have a noticeable impact on the hardness. It should be emphasized that it is advisable to perform the roller burnishing in one stroke since the second and third strokes have a minor impact on the surface condition. However, the use of more than three working strokes is unacceptable, as it will inevitably lead to the "excessive hardening" of the surface due to a sharp increase in the multiplicity of the force application.

Changes in the surface layer during the roller burnishing affect abrasion resistance as it was confirmed by the 2D images (Fig. 10). A spherical wear hole was formed as the result of the impact of the abrasive suspension and the contact sphere on the surface of the samples within $3 \mathrm{~min}$. Even a qualitative analysis of the photographic images, which were obtained after rapid testing, shows how much roller burnishing reduces the wear intensity. We can see that roller burnishing at mode N2 has a more significant effect than at mode N1.

For quantitative estimation of wear intensity of various samples, it is possible to use the experimental data resulted in Figure 11. First, it should be mentioned that the wear of $\mathrm{Fe} / \mathrm{Cu} 15$ samples is more intense than $\mathrm{Fe} / \mathrm{Cu} 20 / \mathrm{Cr} 11 / \mathrm{Ni} 8$ samples under similar test conditions.

Roller burnishing at mode N1 insignificantly reduces (1.2 times) the intensity of samples wear during testing. Roller burnishing at mode N2 provides more significant wear intensity reduction. In particular, the wear rate decreased by 1.6 times for $\mathrm{Fe} / \mathrm{Cu} 15$ material and by 1.5 times for $\mathrm{Fe} / \mathrm{Cu} 20 / \mathrm{Cr} 11 / \mathrm{Ni} 8$ material. At the same time, the effect of surface hardening using roller burnishing becomes more noticeable with increasing testing time. 


\section{Conclusion}

SPD by means of rolling can be considered as a promising method, and the possibilities of this method are not fully explored and exhausted for the parts made of powder alloys. It can be an excellent alternative to strengthening by electro-physical methods, which may increase the cost of manufacturing because of the necessity of acquisition of the expensive process equipment. The apparent advantages of roller burnishing are in its low costs, an absence of industrial waste, and that it can be applied to materials even with low heat resistance.

The complex of experimental results on studying the influence of SPD method as roller burnishing on the wear of working surfaces of parts of submersible pumps made of powder alloy of the $\mathrm{Fe}-\mathrm{Cu}$ system by an example of the guide vane demonstrate the favorable effect of hardening on the performance of the surface layer.

Metallographic analysis of subsurface zones of samples made of composite powder materials after roller burnishing did not show any structural changes, and the microstructure of the surface layers did not differ from the basis of the sample. It is necessary to assume that strengthening of the surface layer was due to an increase in the density of dislocations.

The roller burnishing force (deformation) has a primary influence on roughness, microhardness, and hardness of the surface layer of the samples. As the force increases, the roughness slightly decreases and the hardness increases. This regularity can be observed up to the value of the rolling force of $2650 \mathrm{~N}$. Further increase in the force leads to destabilization of the process and development of the excessive hardening of the surface that makes the surface layer more brittle that it cannot resist further operational loads. The optimal operational force for two types of powder alloys parts is in the narrow range of 2600-2640 N.

Application of hardening using SPD technology SPD provides the decrease in intensity of wear of the samples made of investigated compositions of powder alloys by 1.5-1.6 times in comparison with samples without SPD. The obtained data refer to testing on the stability of a superficial layer to abrasive wear by the Calotest method. The results encourage us to expect some effect in the production tests to be carried out on the surface hardened guide vanes.

Acknowledgements. This project has received funding from the Ministry of Education and Science of the Russian Federation within the framework of the state task for scientific research, under Grant Agreement N9.7889.2017/8.9.

\section{References}

[1] W. Shi, X. Gao, Q. Zhang, et al., Numerical investigations on effect of wear-ring clearance on performance of a submersible well pump, Adv. Mech. Eng. 9 (2017) 1687814017704155

[2] K.V. Litvinenko, S.E. Zdolnik, V.G. Mikhailov, Modeling of the process of deterioration of ESP characteristics under conditions of intensive erosive wear, Oil Ind. 12 (2014) $132-135$
[3] H.M. Zhang, L.X. Zhang, Numerical studies of abrasion wear on the guide vanes in a submersible axial flow pump, Adv. Eng. Res. 20 (2015) 106-108

[4] A. Ori, L. Ceschini, C. Martini, et al., Materials and surface modification technologies for variable displacement oleodynamic vane pumps: evaluation of the tribological behavioura, metallurgia italiana 10 (2009) 19-38

[5] M. Daqiqshirazi, R. Torabi, A. Riasi, et al., The effect of wear ring clearance on flow field in the impeller sidewall gap and efficiency of a low specific speed centrifugal pump, Proc. Inst. Mech. Eng. Part C J. Mech. Eng. Sci. 232 (2018) 3062-3073

[6] V.N. Ivanovsky, A.V. Degovtsov, A.A. Sabirov, S.V. Krivenkov, Influence on the operating time of electric drive centrifugal pump units of pump supply and rotation speed during operation of wells complicated by removal of mechanical impurities, Neftegaz Territory 9 (2017) 58-64

[7] Z. Lu, C. Wang, N. Qiu, et al., Experimental study on the unsteady performance of the multistage centrifugal pump, J. Braz. Soc. Mech. Sci. 40 (2018) UNSP 264

[8] T. Schaefer, M. Neumann, A. Bieberle, et al., Experimental investigations on a common centrifugal pump operating under gas entrainment conditions, Nucl. Eng. Des. 316 (2017) $1-8$

[9] A. Akkurt, Comparison of roller burnishing method with other hole surface finishing processes applied on AISI 304 austenitic stainless steel, J. Mater. Eng. Perform. 20 (2011) 960-968

[10] V. Ostrovsky, M. Perelman, S. Peshcherenko, Mechanism of hydro-abrasive wear of oil pumps' stages, Drilling Oil 10 (2012) 32-34

[11] V. Yu. Fominski, S.N. Grigoriev, A.G. Gnedovets, et al., Pulsed laser deposition of composite Mo-Se-Ni-C coatings using standard and shadow mask configuration, Surf. Coat. Technol. 206 (2012) 5046-5054

[12] S.N. Grigoriev, A.S. Metel, M.A. Volosova, Yu.A. Melnik, Deposition of wear-resistant coatings using a combined source of metal atoms and fast gas molecules, Mech. Ind. 16 (2015) 705

[13] A.M. Abrao, B. Denkena, B. Breidenstein, et al., Surface and subsurface alterations induced by deep rolling of hardened AISI 1060 steel, Prod. Eng. Res. Dev. 8 (2014) 551-558

[14] S.C. Chaudhari, C.O. Yadav, A.B. Damor, A comparative study of mix flow pump impeller CFD analysis and experimental data of submersible pump, Int. J. Res. Eng. Technol. 1 (2013) 57-64

[15] M.M. Stebulyanin, A.A. Gurkina, A.A. Shein, N.Y. Cherkasova, Measuring adhesive bond strength and microhardness of multilayer composite wear-resistant coating, Mech. Ind. 17 (2016) 712

[16] M.M. Akhmedpashaev, M.U. Akhmedpashaev, Zh.B. Begov, Life of submersible-pump components, Russ. Eng. Res. 38 (2018) 752-754

[17] Q. Wei, X. Sun, Performance influence in submersible pump with different diffuser inlet widths, Adv. Mech. Eng. 9 (2017) 1687814016683354

[18] A.S. Metel, S.N. Grigoriev, Yu.A. Melnik, V.V. Prudnikov, Glow discharge with electrostatic confinement of electrons in a chamber bombarded by fast electrons, Plasma Phys. Rep. 37 (2011) 628-637

[19] S.N. Grigoriev, A.S. Metel, M.A. Volosova, Yu.A. Melnik, Surface hardening by means of plasma immersion ion implantation and nitriding in glow discharge with electrostatic confinement of electrons, Mech. Ind. 16 (2015) 711 
[20] M.A. Volosova, S.N. Grigoriev, E.A. Ostrikov, Use of laser ablation for formation of discontinuous (discrete) wearresistant coatings formed on solid carbide cutting tool by electron beam alloying and vacuum-arc deposition, Mech. Ind. 17 (2016) 720

[21] S.N. Grigoriev, A.S. Metel, S.V. Fedorov, Modification of the structure and properties of high-speed steel by combined vacuum-plasma treatment, Met. Sci. Heat Treat. 54 (2012) 8-12

[22] A. Metel, M. Volosova, S. Grigoriev, Yu. Melnik, Products pre-treatment and beam-assisted deposition of magnetron sputtered coatings using a closed cylindrical grid inside a planetary rotation system, Surf. Coat. Technol. 325 (2017) 327-332

[23] O.V. Sobol', A.A. Andreev, S.N. Grigoriev, M.A. Volosova, V.F. Gorban', Vacuum-arc multilayer nanostructured TiN/ Ti coatings: structure, stress state, properties, Met. Sci. Heat Treat. 54 (2012) 28-33

[24] M. Sahin, C. Misirli, D. Özkan, Characteristic properties of AlTiN and TiN coated HSS materials, Ind. Lubr. Tribol. 67 (2015) 172-180

[25] J.K. Katiyar, A. Kumar, B. Pandey, Synthesis of iron-copper alloy using electrical discharge machining, Mater. Manuf. Process. 33 (2018) 1531-1538

[26] P. Chakraborty, S.B. Biner, Crystal plasticity modeling of irradiation effects on flow stress in pure-iron and iron-copper alloys, Mech. Mater. 101 (2016) 71-80

[27] V.N. Antsiferov, A.I. Rabinovich, O.M. Perelman, et al., Method of manufacturing sintered articles, Russian Federation Patent No. 2037382, 19.06.1995

[28] X.L. Yuan, Y.W. Sun, L.S. Gao, et al., Effect of roller burnishing process parameters on the surface roughness and microhardness for TA2 alloy, Int. J. Adv. Manuf. Technol. 85 (2017) 1373-1383

[29] M. Okada, Y. Miyagoshi, M. Otsu, Roller burnishing method with active rotation tool - better surface finish than conventional roller burnishing, Key Eng. Mater. 749 (2017) 9-14

[30] J.J. Kauzlarich, J.A. Williams, Archard wear and component geometry, Proc. Inst. Mech. Eng. Part J J. Eng. Tribol. 215 (2001) 387-403

[31] R.G. Solanki, K.A. Patel, R.B. Dhruv, Parametric optimization of roller burnishing process for surface roughness, J. Mech. Civil Eng. 13 (2016) 21-26

[32] E. Yu. Kropotkina, V.K. Flegentov, Hardening of powder alloy components by rolling, Russ. Eng. Res. 35 (2015) 822-823

[33] S. Kikuchi, Y. Nakamura, K. Nambu, et al., Formation of the hydroxyapatite layer on Ti-6Al-4V ELI alloy by fine particle peening, Int. J. Autom. Technol. 11 (2017) 915-924
[34] M. Okada, H. Kozuka, H. Tachiya, et al., Burnishing process using spherical 5-dof hybrid-type parallel mechanism with force control, Int. J. Autom. Technol. 8 (2014) 243-252

[35] M. Okada, S. Suenobu, K. Watanabe, et al., Development and burnishing characteristics of roller burnishing method with rolling and sliding effects, Mechatronics 29 (2015) $110-118$

[36] G.D. Revankar, R. Shetty, S.S. Rao, et al., Wear resistance enhancement of titanium alloy (Ti-6A1-4V) by ball burnishing process, J. Mater. Res. Technol. 6 (2017) 13-32

[37] M. Kowalik, T. Mazur, T. Trzepiecinski, Assessment of the depth of the deformed layer in the roller burnishing process, Strength Mater. 50 (2018) 493-503

[38] M.R. Stalin John, N. Banerjee, K. Shrivastava, et al., Optimization of roller burnishing process on EN-9 grade alloy steel using response surface methodology, J. Braz. Soc. Mech. Sci. 39 (2017) 3089-3101

[39] Y. Yanagisawa, Y. Kishi, K. Sasaki, Analysis of residual stresses during heat treatment of large forged shafts considering transformation plasticity and creep deformation, Strength Mater. 49 (2017) 239-249

[40] B. Zabkar, J. Kopae, An investigation into roller burnishing, J. Prod. Eng. 16 (2013) 45-48

[41] P. Zhang, J. Lindemann, W.J. Ding, et al., Effect of roller burnishing on fatigue properties of the hot-rolled Mg-12Gd3Y magnesium alloy, Mater. Chem. Phys. 124 (2010) $835-840$

[42] H. Amdouni, H. Bouzaiene, A. Montagne, et al., Modeling and optimization of a ball-burnished aluminum alloy flat surface with a crossed strategy based on response surface methodology, Int. J. Adv. Manuf. Technol. 88 (2017) 801-814

[43] H.-S. Park, T.-T. Nguyen, X.-P. Dang, Multi-objective optimization of turning process of hardened material for energy efficiency, Int. J. Precis. Eng. Manuf. 12 (2016) $1623-1631$

[44] X. Yuan, Y. Sun, C. Li, et al., Experimental investigation into the effect of low plasticity burnishing parameters on the surface integrity of TA2, Int. J. Adv. Manuf. Technol. 88 (2017) 1089-1099

[45] R. Aviles, J. Albizuri, A. Rodriguez, et al., Influence of lowplasticity ball burnishing on the high-cycle fatigue strength of medium carbon AISI 1045 steel, Int. J. Fatigue 55 (2013) 230-244

[46] L. Hiegemann, C. Weddeling, A.E. Tekkaya, Analytical contact pressure model for predicting roughness of ball burnished surfaces, J. Mater. Process. Technol. 232 (2016) $63-77$

Cite this article as: E. Kropotkina, M. Zykova, A. Shein, N. Kapustina, Application of roller burnishing technologies to improve the wear resistance of submerged pump parts made of powder alloys, Mechanics \& Industry 19, 705 (2018) 